\title{
Minireview
}

\section{Insulin-like growth factors and insulin control a multifunctional signalling network of significant importance in cancer}

\author{
P Massoner ${ }^{*, 1}$, M Ladurner-Rennau', IE Eder' and H Klocker' \\ 'Section of Experimental Urology, Department of Urology, Innsbruck Medical University, Anichstr. 35, Innsbruck 6020, Austria
}

Insulin-like growth factor (IGF) and insulin (INS) proteins regulate key cellular functions through a complex interacting multicomponent molecular network, known as the IGF/INS axis. We describe how dynamic and multilayer interactions give rise to the multifunctional role of the IGF/INS axis. Furthermore, we summarise the importance of the regulatory IGF/INS network in cancer, and discuss the possibilities and limitations of therapies targeting the IGF/INS axis with reference to ongoing clinical trials concerning the blockage of IGFIR in several types of cancer.

British Journal of Cancer (2010) I 03, |479-|484. doi:I0.1038/sj.bjc.6605932 www.bjcancer.com

Published online 5 October 2010

(c) 2010 Cancer Research UK

Keywords: cancer therapy; IGF; insulin

\section{IGF/INS PROTEINS CONTROL AN INTERACTING MULTIFUNCTIONAL REGULATORY NETWORK}

Insulin-like growth factor (IGF) and insulin (INS) proteins orchestrate a regulatory network of multiple components with dynamic interactions, named herein the IGF/INS axis. Insulin-like growth factor/INS proteins regulate crucial functions in tissue homeostasis and malignant growth, including proliferation, survival, tissue homeostasis, differentiation, energy supply, energy consumption and cellular metabolism. The main sources of circulating IGFs and INS are the liver and $\beta$-cells of the islets of Langerhans of the pancreas, respectively. In addition, there are local productions of IGFs and INS in many cells and tissues.

The IGF/INS axis is composed of the receptor ligands IGF1, IGF2 and INS, high-affinity (IGFBP) and low-affinity (IGFBP-rP) IGF-binding proteins that exert modulatory functions, and the receptors IGF1 receptor (IGF1R), IGF2 receptor (IGF2R), INS receptor (INSR) and INSR-related receptor (IRR). Upon activation, IGF/INSRs initiate a complex intracellular signaling network across the major signaling pathways PI3K-AKT and RAS-RAFMAPK, and thus control a variety of cellular processes in normal physiology and pathophysiology.

\section{MULTIFUNCTIONAL EFFECTS IN PHYSIOLOGY AND PATHOPHYSIOLOGY}

To date, 15 molecular functions and 29 biological processes have been linked to IGF1R, whereas 22 molecular functions and 47 biological processes have been linked to INSR in the gene ontology database (http://www.geneontology.org; definitions: molecular function, the elemental activities of a gene product at the molecular level; biological process, operations or sets of molecular

\footnotetext{
*Correspondence: Dr P Massoner;

E-mail: Petra.Massoner@i-med.ac.at

Received II May 2010; revised I September 2010; accepted

7 September 20I0; published online 5 October 2010
}

events with a defined beginning and end, pertinent to the functioning of integrated living units: cells, tissues, organs and organisms. Query August 2010). This shows that the IGF/INS axis is a multifunctional protein family and we can provide only an outline of the best-characterised IGF/INS effects. The reader should keep in mind the fact that the IGF/INS multifunctional network will have additional functions, depending on the cell type and the cellular context.

IGF/INS proteins are expressed ubiquitously, but in different ratios and amounts, and exert auto-, para- and endocrine biological effects in a variety of tissues and cells: (1) IGF/INS growth factors act as growth hormones and regulate the growth of human tissues and cells (Pollak, 2008). Severe growth retardations were found in humans with defects in IGF/INS genes (Ohlsson et al, 2009), whereas studies in knockout mice have confirmed the pivotal role of the IGF/INS axis in normal growth (Ohlsson et al, 2009). Regulation of the life span has been associated with IGF expression levels (Holzenberger et al, 2003). (2) The IGF/INS axis is required to maintain tissue homeostasis (Sutherland et al, 2008) and a differentiated phenotype in normal tissue (Belfiore et al, 2009). (3) The IGF/INS network influences the balance between apoptosis and survival. IGFs are anti-apoptotic and pro-survival factors-effects that are of major importance in the emergence and progression of cancer (LeRoith and Roberts, 2003; Pollak, 2008). (4) A further important function of the IGF/INS network is in metabolism, where INS is a key regulator controlling cellular glucose, amino-acid and fatty-acid uptake, as well as glycogen, lipid and protein synthesis and a variety of other related metabolic processes (Saltiel and Kahn, 2001). (5) The IGF/INS network is also involved in angiogenesis, cell adhesion, migration and wound healing (LeRoith and Roberts, 2003) and (6) (less known) exerts multiple effects in the brain. It also influences mammalian behavior and memory (Broughton and Partridge, 2009; Ohlsson et al, 2009).

We do not entirely know how the IGF/INS axis mediates these multiple functions, but experimental data have shown that dynamic and multilayer IGF/INS interactions, and cross talks of 


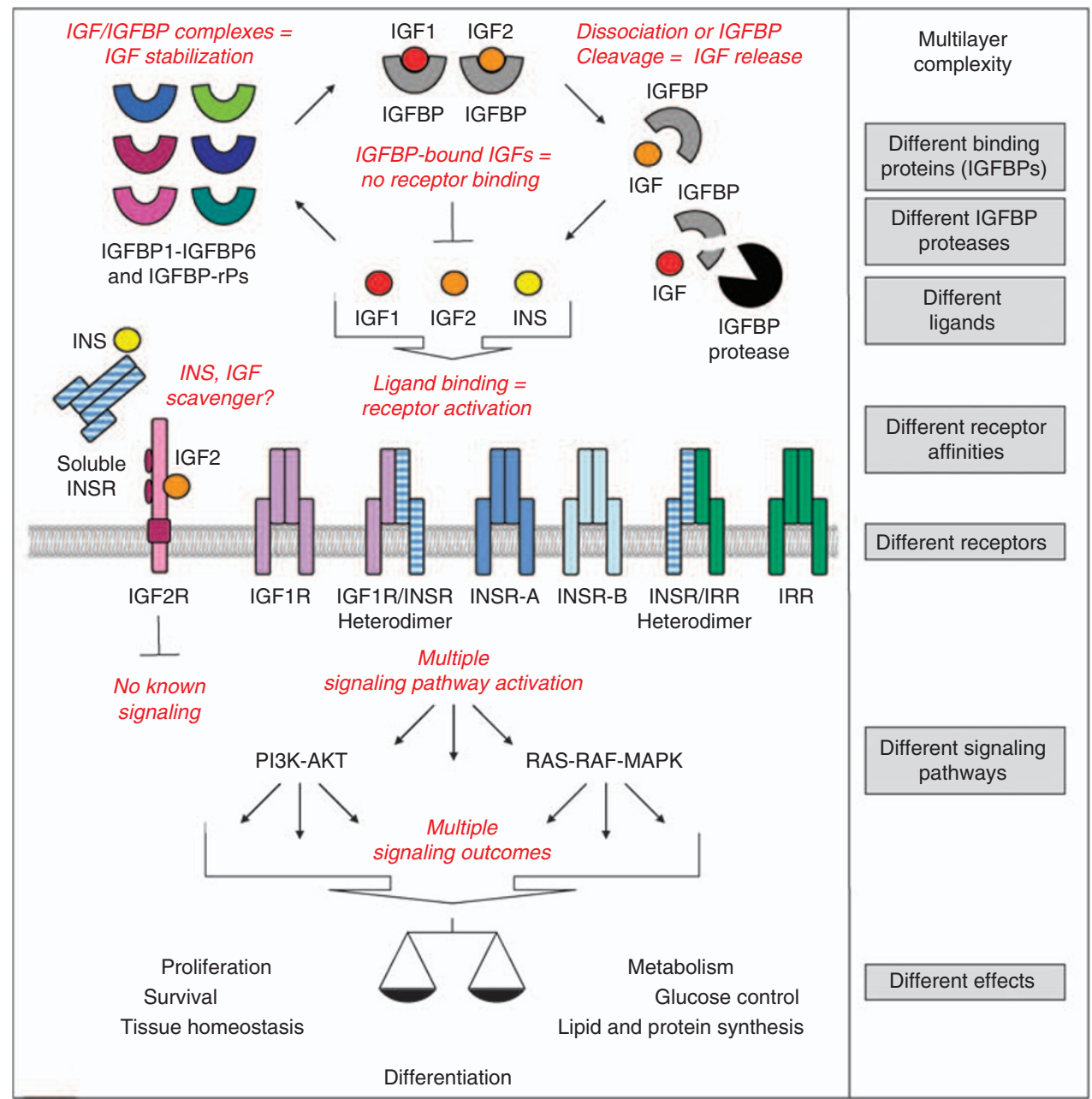

Figure I The IGF/INS axis is a complex multilayer interacting molecular network with multiple effects.

the IGF/INS axis to other receptor tyrosine kinase pathways, such as the epidermal growth factor receptor (EGFR) pathway, generate variable IGF/INS signals in different cell types and tissues. The different layers of diversity of signalling that give rise to the multiple functions of the IGF/INS axis are schematically shown in Figure 1 and explained in the following chapters. The variety of cellular responses to the IGF/INS signal depend, on one hand, on the availability of growth factors and the ratios of the receptors and signalling molecules, and, on the other hand, on the cell and tissue type and the tissue microenvironment.

\section{IGF/INSRS - COMPLEXITY THROUGH HETERODIMER FORMATION}

IGF/INSRs include IGF1R, IGF2R, INSR, the latter existing in two different isoforms, namely INSR-A and INSR-B, and IRR. IGF1R, INSR and IRR are composed of an extracellular ligand-binding domain and an intracellular protein kinase domain. Their structural similarity permits the formation of heterodimer receptors formed by subunits of different receptor proteins, such as IGF1R/INSR and INSR/IRR heterodimers (Jui et al, 1996; Pandini et al, 2002). Heterodimers are spontaneously formed when the different receptors are expressed, and are the most abundant receptor subtype in many tissues.

The receptors bind IGF and INS ligands with different affinities: Ranking from high to low and very low affinity, IGF1R binds IGF1,
IGF2 and INS; IGF2R binds IGF2 and other ligands, such as mannose-6-phosphate, IGF1 and INS; and INSR binds INS, IGF2 and IGF1 (Pandini et al, 2002; Ghosh et al, 2003; Belfiore et al, 2009). INSR-A has a higher IGF2 affinity than INSR-B (Belfiore et al, 2009). IRR is an orphan receptor with unknown binding ligand that participates in signal transduction as a heterodimerisation partner of the ligand-binding family members (Zhang and Roth, 1992). Evidently, the subunit composition of receptors determines their affinity for ligands. For instance, IGF1R/INSR-A heterodimers possess a high affinity for IGF2 (Pandini et al, 2002; Belfiore et al, 2009).

It is of note that IGF1R/EGFR heterodimers have also been characterised (Morgillo et al, 2006), but their abundance and ligand affinity remain unclear. A few reports describe the occurrence of a soluble INSR that is secreted from cultured human cells (Papa et al, 1993) and appears in human plasma (Pezzino et al, 1992). This soluble INSR was shown to bind INS (Papa et al, 1993); its IGF binding has not yet been investigated.

Taken together, the classical view that IGFs bind and activate IGF1R and INS activates INSR greatly simplifies the biological situation in which IGF/INS-responsive receptors constitute a complex interacting receptor network. Depending on the availability of IGF/INS ligands and the ratios of IGF/INS-responsive receptors, IGFs can also activate INSR and, conversely, INS activates IGF1R. 


\section{IGF BINDING PROTEINS MODULATE RECEPTOR LIGANDS}

IGF1 and IGF2 are bound by six high-affinity binding proteins, named IGFBP from IGFBP1 to IGFBP6, and several low-affinity binding proteins, known as IGFBP-related proteins (IGFBP-rPs). IGFBPs and IGFBP-rPs have different degrees of IGF affinity: IGFBP1 - IGFBP5 have higher affinities for IGF1, whereas IGFBP6 has a higher affinity for IGF2 (Firth and Baxter, 2002). Moreover, IGFBPs and IGFBP-rPs have the ability to bind INS, but with a very low affinity (Hwa et al, 1999).

IGF/IGFBP complexes exert two principal functions: first, they stabilise IGFs and protect them from degradation, thus extending their lifespan from a few minutes to several hours. Second, they inhibit the binding of IGFs to their receptors. Therefore, only IGFs that are released from IGFBPs by dissociation or proteasemediated IGFBP cleavage can induce IGF signals (reviewed by Hwa et al, 1999; Firth and Baxter, 2002).

In general, these IGF-related effects are similar and, in part, redundant for all IGFBPs. However, different IGFBP affinities, structures and post-translational modifications (Hwa et al, 1999), as well as the presence of specific IGFBP proteases (Sadowski et al, 2003) and IGFBP-binding extracellular matrix components (Nam et al, 2002), influence the effects of IGFBPs and permit fine-tuning of IGF/IGFBP interactions in different tissues and tissue areas. IGFBP binding to IGFs is usually inhibitory for receptor activation, but under certain circumstances IGFBPs can promote IGF signalling and may have pro-oncogenic effects. IGFBPs stabilise and slowly release IGFs for receptor interactions, thereby preventing receptor downregulation by high IGF exposure. Thus, they promote a prolonged and constant receptor activation (Firth and Baxter, 2002).

Beside their functions in IGF complexes, IGFBPs and IGFBP-rPs exert effects that are independent of IGF binding or signalling and specific for single IGFBPs and IGFBP-rPs. For instance, IGFBP-3 was found to act as an anti-cancer protein by inhibiting proliferation, adhesion and motility by IGF-independent mechanisms (Firth and Baxter, 2002). IGFBP-rP1 (IGFBP7) was described to have a central role in BRAF-mediated senescence and apoptosis in melanoma cells (Wajapeyee et al, 2008). Taken together, IGF/IGFBP complexes are tightly regulated and highly dynamic extracellular complexes that modulate the IGF/INS signal by influencing IGF/INS ratios, growth factor stabilities, receptor binding and duration of receptor activation.

\section{IGF/INSR DOWNSTREAM SIGNALLING PATHWAYS}

IGF1R, INSR and IRR are tyrosine kinase receptors that initiate an intracellular signal upon receptor activation. The signal transduction is mediated by both homo- and heterodimer receptors. Not only in homodimers but also in heterodimers both parts of the receptor can be activated upon ligand binding. Thus, IGF1R/INSR heterodimers activate IGF1R and INSR signalling (Belfiore et al, 2009), and INSR/IRR heterodimers activate INSR, and also the orphan IRR (Zhang and Roth, 1992).

IGF2R has no apparent intracellular signal and is believed to act as a scavenger receptor for IGFs. The main function of IGF2R is related to other pathways rather than IGF signalling: IGF2R is required for the delivery of acid hydrolases from the Golgi network to endosomes and lysosomes (Ghosh et al, 2003). The role of the soluble INSR in the IGF/INS axis is yet to be investigated, but the soluble INSR may also well function as a scavenger receptor, thereby reducing the extracellular availability of INS.

IGF/INS signal transduction may be summarised as follows: IGF/INS binding to IGF1R and INSR homo- and heterodimers induces receptor clustering, autophosphorylation, and stimulation of receptor tyrosine kinase activity, leading to the recruitment and phosphorylation of IRS-1 and Shc, which activate (directly or by association with Grb-2/SOS) the two signalling pathways
PI3K-AKT and RAS-RAF-MAPK. These pathways, in turn, initiate a variety of intracellular signalling cascades that have multiple effects on gene regulation and protein expression, activation and translocation (LeRoith and Roberts, 2003). However, the IGF/INS signal is more complex than this simplified view suggests: a variety of other substrates for IGF1R and INSR, such as other IRSs, Gab1, Cbl, APS, SHP2, Fyn and Csk, have been described (Belfiore et al, 2009). Availability, location and ratios of these receptor substrates significantly influence cellular responses upon IGF1R and INSR activation. Some of the main signalling molecules, such as PI3K, appear in different isoforms that have different activation and effector properties (Saltiel and Kahn, 2001). Several cross-talks of the IGF/INS signalling to other pathways have been reported, which are mediated by interactions of IGF1R and INSR with major signalling molecules of other molecular pathways, such as SOCS interactions influencing the JAK-STAT pathway (Dey et al, 1998), or interactions with other receptors, such as IGF1R/EGFR heterodimers (Morgillo et al, 2006). Thus, IGFs and INS activate, by means of IGF1R and INSR, a highly complex intracellular signaling network (Figure 2).

IGF1R and INSR have been reported to act through the same pathways. However, subtle differences in the recruitment of docking proteins and intracellular mediators cause a fine-tuned signalling outcome that permits selective IGF1R or INSR signal transduction (Pandini et al, 2002). These differences arise not only by different substrate specificities for IGF1R and INSR, which probably do exist, but are also mediated by different binding velocities, reaction times, activities, expression levels and sub-cellular locations of signalling molecules (Sasaoka et al, 1996; Biedi et al, 2003).

In summary, IGF/INS ligand binding leads to the activation of IGF1R, INSR and IRR, which activate a complex signalling network across the two major signalling pathways PI3K-AKT and RASRAF-MAPK. With regard to the close and reciprocal interactions of INS and IGF signalling in the IGF/INS network, the activation of a single pathway (such as IGF signalling) with no activation of the other pathway (such as INS signalling) appears to be unlikely. However, fine-tuning of ligand availability, receptor ratios, signalling molecule expression and localisation alter the signal, thus allowing predominant activation of IGF/IGF1R or INS/INSR signals in different cells and tissues.

\section{THE IGF/INS AXIS AND CANCER}

Evasion from apoptosis and a limitless replicative potential are two hallmarks of cancer (Hanahan and Weinberg, 2000). Thus, growth and survival pathways have emerged as appealing targets for cancer therapy. As the IGF axis is a central regulator of growth and survival, therapeutic strategies focusing on the blockage of IGF1R and IGF signalling are currently being investigated for several types of cancer in a large number of clinical trials. In the following we will discuss the rationale underlying these trials, their power and their limitations in respect of the IGF/INS network.

Cumulative evidence has been obtained concerning the role of the IGF/INS network in the emergence and progression of cancer. Genetic studies showed that the risk of cancer is influenced by IGF/INS gene variants, and cancer-associated somatic copy number variations are found in IGF/INS gene regions. Recent examples are an IGF1 polymorphism associated with non-smallcell lung cancer (Zhang et al, 2010), an IGF2R polymorphism influencing the risk of oesophageal and gastric cancer (Hoyo et al, 2009), and the detection of a cancer-associated somatic copy number amplification in the IGF1R gene region in a pooled analysis of 26 cancer types, each represented by more than 20 specimens (Beroukhim et al, 2010). Epidemiological studies also revealed that high IGF1 serum concentrations are associated with prostate, colorectal and breast cancer (Renehan et al, 2004). Epigenetic, expression and protein analyses have demonstrated 


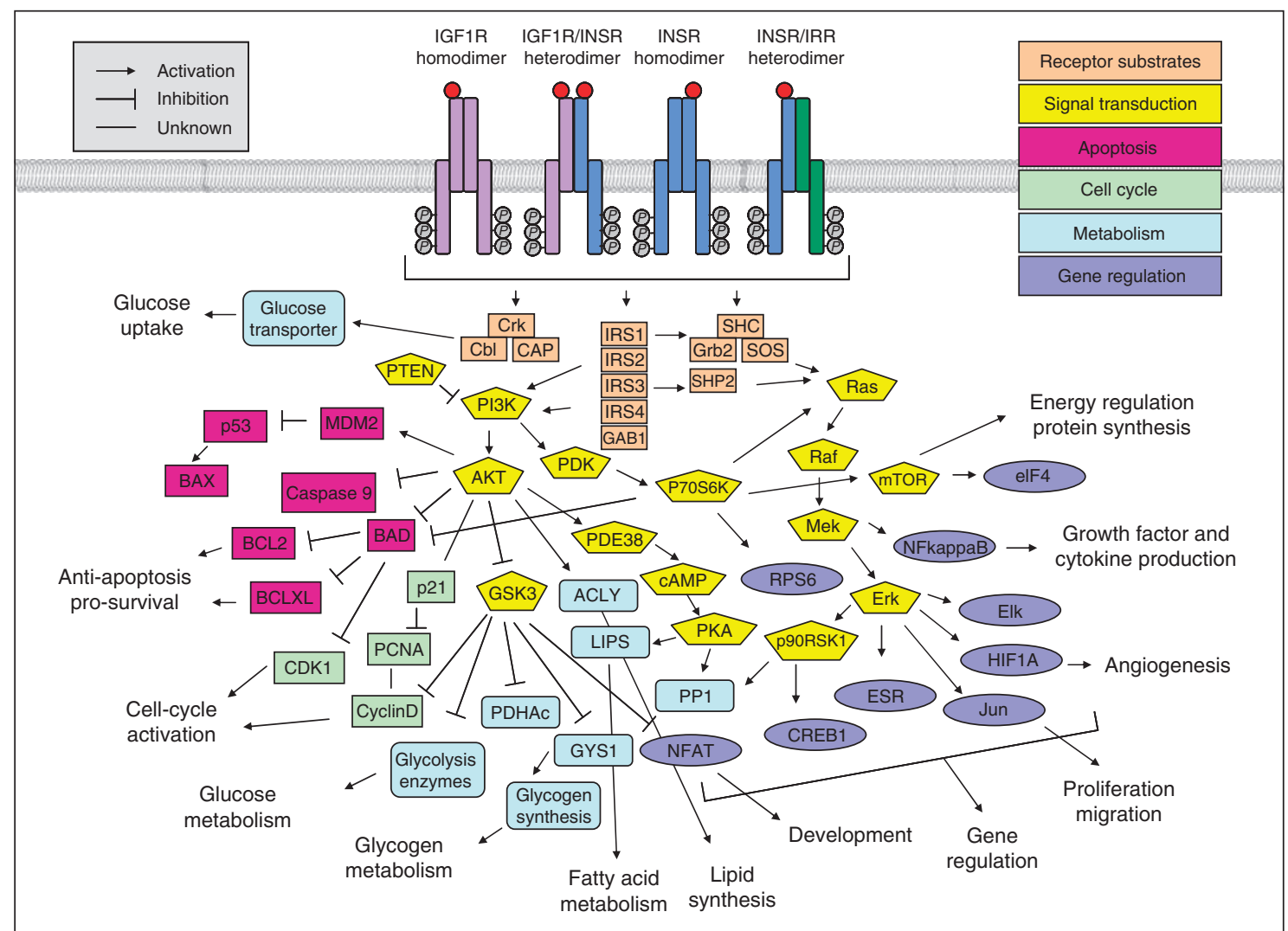

Figure 2 IGF/INS ligand binding, to one or both receptor monomers, leads to the activation of IGFIR, INSR and IRR, which activate a complex signalling network across the two major signalling pathways PI3K-AKT and RAS-RAF-MAPK (shown here in parts (for detailed signalling networks see Kyoto Encyclopedia of Genes and Genomes pathway database (http://www.genome.jp/keg) and GeneGO pathway analysis database (http://www.genego.com)). The IGF/INS axis regulates multiple functions in normal physiology and pathophysiology. IGFIR and INSR have been reported to act by means of the same pathways. The signal is influenced by different binding velocities, reaction times, activities, expression levels and sub-cellular locations of signalling molecules. Selective substrate specificities for IGFIR and INSR probably also exist.

alterations of IGF/INS expression and protein levels in cancer tissues. Increased expression of IGF2 caused by loss of genomic IGF2 imprinting (genomic imprinting: only one allele of the gene is active, depending on the parental origin) was registered for cervical cancer, choriocarcinoma, colorectal cancer, hepatoblastoma, lung cancer, rhabdomyosarcoma, pediatric testicular cancer and Wilms' tumours (Ross et al, 1999; Chao and D'Amore, 2008). IGF1R was found to be essential for oncogenic transformation in certain cellular systems. Mouse fibroblasts lacking IGF1R cannot be transformed by known oncogenes, such as SV40 T antigen, papillomavirus E5 and overexpression of Ras (Sell et al, 1993). Overexpression of a constitutively activated IGF1R was shown to be sufficient to cause mammary epithelial cell transformation in mouse models (Jones et al, 2007; Kim et al, 2007). In prostate epithelial cells, however, re-expression of the IGF1R inhibited the malignant phenotype of SV40 T antigen immortalised human prostate epithelial cells (Plymate et al, 1997). Epithelialspecific deletion of $I G F 1 R$ accelerated the emergence of aggressive prostate cancer when p53 activity was compromised (Sutherland et al, 2008). These observations underscore the importance of the IGF axis in carcinogenesis and tumour progression and, on the other hand, show again that IGF/INS effects are variable in different cell and tissue types, including cancer.

\section{IGF1R AS A TARGET FOR CANCER THERAPY}

In current clinical trials, the main IGF/INS target for cancer therapy is IGF1R. Other IGF/INS targets are approached indirectly:
IGFs are addressed by the use of somatostatin analogues, which suppress their production, and IGF/INSRs through blockage of receptor downstream molecules, using PI3K and AKT inhibitors among other substances. More than 70 clinical trials investigating the blockage of IGF1R are under way. Different anti-IGF1R antibodies, as well as small-molecule IGF1R or IGF1R tyrosine kinase inhibitors, are being investigated as stand-alone therapies or in combination with conventional treatments for many cancers, including breast cancer, colorectal cancer, leukaemia (ALL, CML), non-small-cell lung cancer, ovarian cancer, pancreatic cancer, prostate cancer and sarcoma (recently discussed and summarised in Gualberto and Pollak, 2009). Most anti-IGF1R antibodies are reported to be monospecific for IGF1R, whereas several smallmolecule inhibitors also inhibit IGF1R/INSR heterodimers and INSR. Preliminary outcomes have suggested that the treatment is well tolerated, although effects on metabolism, such as elevated levels of circulating IGF1, INS and glucose levels, have been reported. In some cases, anti-diabetic treatment was required to control blood glucose levels (Gualberto and Pollak, 2009). The efficacy of the treatment has not been fully explored thus far, but encouraging data have been registered in a phase-II study concerning the use of an anti-IGF1R antibody in non-small-cell lung cancer. Promising results of anti-IGF1R therapy have also been reported on patients with sarcomas in phase-I studies (Gualberto and Pollak, 2009). These early studies justify the investigation of IGF1R as a target for cancer therapy. However, a phase-III study with an anti-IGF1R antibody combined with erlotinib in advanced non-small-cell lung cancer was terminated recently for safety reasons and lack of efficiency (ClinicalTrials.gov Identifier: NCT00673049). 
These results show that the IGF1R is a challenging target for cancer therapy. Clinical trials targeting IGF1R must be designed and controlled with care. Several limitations arise from the complexity and multiple functions of the IGF/INS axis: (a) The IGF/INS axis is a molecular network that exerts essential functions in normal tissues (e.g. control of growth processes, tissue homeostasis, differentiation and metabolism). Interfering with the IGF/INS network may, therefore, cause severe side effects in some tissues and cells. (b) A single anti-IGF1R therapy may be inefficient. Resistance to anti-IGF1R therapy can occur because of signal transduction by IGF/INS heterodimer receptors and redundant effects with INSR. It was recently shown in a mouse model for pancreatic neuroendocrine cancer that resistance to anti-IGF1R therapy was overcome by disruption of the INSR gene (Ulanet et al, 2010). Furthermore, mutations in major IGF1R signalling molecules, such as the tumor suppressor PTEN affecting the PI3K-AKT pathway (Zhao et al, 2004), and cross-talks with other molecular pathways, such as EGFR (Morgillo et al, 2006; Huang et al, 2009), can cause anti-IGF1R therapy resistance. (c) A combined therapy targeted against IGF1R and INSR may be more efficient, but will also affect glucose metabolism and provoke diabetic symptoms. A combined therapy targeting IGF1R and EGFR was shown to successfully inhibit tumour cells, which were resistant to IGF1R blockage by overexpressing the EGFR pathway (Huang et al, 2009). (d) Although IGF1R was reported to be overexpressed in a variety of cancers, in some tumours the IGF signal exerts a protective effect against tumour formation (Lewis et $a l, 2009$ ) and inhibits the emergence of an aggressive tumour phenotype (Sutherland et al, 2008).

Taken together, the data reported thus far suggest that IGF1R is an interesting target in cancer. However, several limitations arise from the complexity and multifunctional role of the IGF/INS axis. To overcome these limitations, a combined therapy focused on IGF1R and other targets, such as EGFR, is a promising treatment strategy for some types of cancer, but the patients must be selected with great care to avoid severe side effects.

\section{FUTURE DIRECTIONS}

Reports from clinical trials give reason for optimism regarding the use of IGF1R inhibitors in cancer patients. At the same time, however, in some trials severe side effects and resistance to antiIGF1R treatment were observed. To control, predict and - in best case - avoid side effects, we need a better understanding of the function of the IGF/INS pathway in normal physiology, including implications of the IGF/INS axis in normal growth, development, differentiation and cellular metabolism. Furthermore, we need new molecular markers to identify patients profiting of an anti-IGF1R therapy. The clinical success of nearly all tyrosine kinase inhibitors is predicted by appropriate tumour characterisation, such as the presence of mutations or receptor overexpression. An elegant approach to how such a characterisation could be achieved was described by de Bono and coworkers. They confirmed the expression of IGF1R by analysing circulating tumour cells (de Bono et al, 2007). Such an analysis - extended to additional molecular markers similar to IGF1R/EGFR expression levels and receptor mutations, as well as alterations of key signalling molecules, such as PTEN, p53 or k-ras - may help to achieve individual tumour characterisation to increase response rates to treatment, reduce side effects and avoid therapy resistance.

\section{CONCLUSION}

In the IGF/INS axis, IGF and INS proteins functionally cross-talk with each other and form a dynamic mutually interacting multilayer molecular network. This regulatory network exerts multiple functions in normal physiology, but is also implicated in the emergence and progression of cancer. Clinical trials with drugs blocking IGF1R are in progress; their preliminary results have been promising. However, the complexity, multiple functions, and interactions of the IGF/INS axis are limiting factors, which may cause side effects, as well as therapy resistance and pose a challenge for accurate patient selection.

Extensive research in the last few decades has provided important insights into the functions of the IGF/INS axis. Future work should be aimed at a better understanding of the axis as a whole, its role in normal physiology and pathophysiology, and the implications of the manipulation of different components - for example, with the help of systems biology approaches - to establish mechanism-based use of inhibitors for the treatment of cancer and other diseases.

\section{ACKNOWLEDGEMENTS}

We apologise to the many investigators whose work we have been unable to cite because of the limit on the number of references. However, some of these colleagues have been included in the cited reviews. We thank Isabel Heidegger and the reviewers of the British Journal of Cancer for their helpful suggestions, and acknowledge financial support from the Austrian Cancer Society/ Tirol and the COMET Center Oncotyrol.

\section{REFERENCES}

Belfiore A, Frasca F, Pandini G, Sciacca L, Vigneri R (2009) Insulin receptor isoforms and insulin receptor/insulin-like growth factor receptor hybrids in physiology and disease. Endocr Rev 30: 586-623

Beroukhim R, Mermel CH, Porter D, Wei G, Raychaudhuri S, Donovan J, Barretina J, Boehm JS, Dobson J, Urashima M, Mc Henry KT, Pinchback RM, Ligon AH, Cho YJ, Haery L, Greulich H, Reich M, Winckler W, Lawrence MS, Weir BA, Tanaka KE, Chiang DY, Bass AJ, Loo A, Hoffman C, Prensner J, Liefeld T, Gao Q, Yecies D, Signoretti S, Maher E, Kaye FJ, Sasaki H, Tepper JE, Fletcher JA, Tabernero J, Baselga J, Tsao MS, Demichelis F, Rubin MA, Janne PA, Daly MJ, Nucera C, Levine RL, Ebert BL, Gabriel S, Rustgi AK, Antonescu CR, Ladanyi M, Letai A, Garraway LA, Loda M, Beer DG, True LD, Okamoto A, Pomeroy SL, Singer S, Golub TR, Lander ES, Getz G, Sellers WR, Meyerson M (2010) The landscape of somatic copy-number alteration across human cancers. Nature 463: 899-905

Biedi C, Panetta D, Segat D, Cordera R, Maggi D (2003) Specificity of insulin-like growth factor I and insulin on Shc phosphorylation and Grb2 recruitment in caveolae. Endocrinology 144: 5497-5503

Broughton S, Partridge L (2009) Insulin/IGF-like signalling, the central nervous system and aging. Biochem J 418: $1-12$

Chao W, D'Amore PA (2008) IGF2: epigenetic regulation and role in development and disease. Cytokine Growth Factor Rev 19: $111-120$

de Bono JS, Attard G, Adjei A, Pollak MN, Fong PC, Haluska P, Roberts L, Melvin C, Repollet M, Chianese D, Connely M, Terstappen LW, Gualberto A (2007) Potential applications for circulating tumor cells expressing the insulin-like growth factor-I receptor. Clin Cancer Res 13: $3611-3616$

Dey BR, Spence SL, Nissley P, Furlanetto RW (1998) Interaction of human suppressor of cytokine signaling (SOCS)-2 with the insulin-like growth factor-I receptor. J Biol Chem 273: 24095-24101

Firth SM, Baxter RC (2002) Cellular actions of the insulin-like growth factor binding proteins. Endocr Rev 23: 824-854

Ghosh P, Dahms NM, Kornfeld S (2003) Mannose 6-phosphate receptors: new twists in the tale. Nat Rev Mol Cell Biol 4: 202-212 
Gualberto A, Pollak M (2009) Emerging role of insulin-like growth factor receptor inhibitors in oncology: early clinical trial results and future directions. Oncogene 28: 3009-3021

Hanahan D, Weinberg RA (2000) The hallmarks of cancer. Cell 100: $57-70$

Holzenberger M, Dupont J, Ducos B, Leneuve P, Geloen A, Even PC, Cervera P, Le Bouc Y (2003) IGF-1 receptor regulates lifespan and resistance to oxidative stress in mice. Nature 421: $182-187$

Hoyo C, Schildkraut JM, Murphy SK, Chow WH, Vaughan TL, Risch H, Marks JR, Jirtle RL, Calingaert B, Mayne S, Fraumeni Jr J, Gammon MD (2009) IGF2R polymorphisms and risk of esophageal and gastric adenocarcinomas. Int J Cancer 125: 2673-2678

Huang F, Greer A, Hurlburt W, Han X, Hafezi R, Wittenberg GM, Reeves K, Chen J, Robinson D, Li A, Lee FY, Gottardis MM, Clark E, Helman L, Attar RM, Dongre A, Carboni JM (2009) The mechanisms of differential sensitivity to an insulin-like growth factor-1 receptor inhibitor (BMS536924) and rationale for combining with EGFR/HER2 inhibitors. Cancer Res 69: $161-170$

Hwa V, Oh Y, Rosenfeld RG (1999) The insulin-like growth factor-binding protein (IGFBP) superfamily. Endocr Rev 20: $761-787$

Jones RA, Campbell CI, Gunther EJ, Chodosh LA, Petrik JJ, Khokha R, Moorehead RA (2007) Transgenic overexpression of IGF-IR disrupts mammary ductal morphogenesis and induces tumor formation. Oncogene 26: 1636-1644

Jui HY, Accili D, Taylor SI (1996) Characterization of a hybrid receptor formed by dimerization of the insulin receptor-related receptor (IRR) with the insulin receptor (IR): coexpression of cDNAs encoding human IRR and human IR in NIH-3T3 cells. Biochemistry 35: $14326-14330$

Kim HJ, Litzenburger BC, Cui X, Delgado DA, Grabiner BC, Lin X, Lewis MT, Gottardis MM, Wong TW, Attar RM, Carboni JM, Lee AV (2007) Constitutively active type I insulin-like growth factor receptor causes transformation and xenograft growth of immortalized mammary epithelial cells and is accompanied by an epithelial-to-mesenchymal transition mediated by NF-kappaB and snail. Mol Cell Biol 27: 3165-3175

LeRoith D, Roberts Jr CT (2003) The insulin-like growth factor system and cancer. Cancer Lett 195: $127-137$

Lewis DA, Travers JB, Somani AK, Spandau DF (2009) The IGF-1/IGF-1R signaling axis in the skin: a new role for the dermis in aging-associated skin cancer. Oncogene 29: 1475-1485

Morgillo F, Woo JK, Kim ES, Hong WK, Lee HY (2006) Heterodimerization of insulin-like growth factor receptor/epidermal growth factor receptor and induction of survivin expression counteract the antitumor action of erlotinib. Cancer Res 66: 10100-10111

Nam T, Moralez A, Clemmons D (2002) Vitronectin binding to IGF binding protein-5 (IGFBP-5) alters IGFBP-5 modulation of IGF-I actions. Endocrinology 143: $30-36$

Ohlsson C, Mohan S, Sjogren K, Tivesten A, Isgaard J, Isaksson O, Jansson JO, Svensson J (2009) The role of liver-derived insulin-like growth factor-I. Endocr Rev 30: 494-535

Pandini G, Frasca F, Mineo R, Sciacca L, Vigneri R, Belfiore A (2002) Insulin/insulin-like growth factor I hybrid receptors have different biological characteristics depending on the insulin receptor isoform involved. J Biol Chem 277: 39684-39695
Papa V, Russo P, Gliozzo B, Goldfine ID, Vigneri R, Pezzino V (1993) An intact and functional soluble form of the insulin receptor is secreted by cultured cells. Endocrinology 133: $1369-1376$

Pezzino V, Papa V, Costantino A, Frittitta L, Russo P, Goldfine ID, Vigneri $R$ (1992) Identification and initial characterization of insulin receptorlike immunoreactivity in human plasma. J Clin Endocrinol Metab 74: $1116-1121$

Plymate SR, Bae VL, Maddison L, Quinn LS, Ware JL (1997) Reexpression of the type 1 insulin-like growth factor receptor inhibits the malignant phenotype of simian virus $40 \mathrm{~T}$ antigen immortalized human prostate epithelial cells. Endocrinology 138: $1728-1735$

Pollak M (2008) Insulin and insulin-like growth factor signalling in neoplasia. Nat Rev Cancer 8: 915-928

Renehan AG, Zwahlen M, Minder C, O’Dwyer ST, Shalet SM, Egger M (2004) Insulin-like growth factor (IGF)-I, IGF binding protein-3, and cancer risk: systematic review and meta-regression analysis. Lancet 363: 1346-1353

Ross JA, Schmidt PT, Perentesis JP, Davies SM (1999) Genomic imprinting of H19 and insulin-like growth factor-2 in pediatric germ cell tumors. Cancer 85: $1389-1394$

Sadowski T, Dietrich S, Koschinsky F, Sedlacek R (2003) Matrix metalloproteinase 19 regulates insulin-like growth factor-mediated proliferation, migration, and adhesion in human keratinocytes through proteolysis of insulin-like growth factor binding protein-3. Mol Biol Cell 14: $4569-4580$

Saltiel AR, Kahn CR (2001) Insulin signalling and the regulation of glucose and lipid metabolism. Nature 414: 799-806

Sasaoka T, Ishiki M, Sawa T, Ishihara H, Takata Y, Imamura T, Usui I, Olefsky JM, Kobayashi M (1996) Comparison of the insulin and insulinlike growth factor 1 mitogenic intracellular signaling pathways. Endocrinology 137: 4427-4434

Sell C, Rubini M, Rubin R, Liu JP, Efstratiadis A, Baserga R (1993) Simian virus 40 large tumor antigen is unable to transform mouse embryonic fibroblasts lacking type 1 insulin-like growth factor receptor. Proc Natl Acad Sci USA 90: 11217-11221

Sutherland BW, Knoblaugh SE, Kaplan-Lefko PJ, Wang F, Holzenberger M, Greenberg NM (2008) Conditional deletion of insulin-like growth factor-I receptor in prostate epithelium. Cancer Res 68: 3495-3504

Ulanet DB, Ludwig DL, Kahn CR, Hanahan D (2010) Insulin receptor functionally enhances multistage tumor progression and conveys intrinsic resistance to IGF-1R targeted therapy. Proc Natl Acad Sci USA 107: $10791-10798$

Wajapeyee N, Serra RW, Zhu X, Mahalingam M, Green MR (2008) Oncogenic BRAF induces senescence and apoptosis through pathways mediated by the secreted protein IGFBP7. Cell 132: $363-374$

Zhang B, Roth RA (1992) The insulin receptor-related receptor. Tissue expression, ligand binding specificity, and signaling capabilities. J Biol Chem 267: $18320-18328$

Zhang M, Hu Z, Huang J, Shu Y, Dai J, Jin G, Tang R, Dong J, Chen Y, Xu L, Huang X, Shen $\mathrm{H}$ (2010) A $3^{\prime}$-untranslated region polymorphism in IGF1 predicts survival of non-small cell lung cancer in a Chinese population. Clin Cancer Res 16: 1236 - 1244

Zhao H, Dupont J, Yakar S, Karas M, LeRoith D (2004) PTEN inhibits cell proliferation and induces apoptosis by downregulating cell surface IGF-IR expression in prostate cancer cells. Oncogene 23: 786-794 